\title{
Música e VOZ PARA ALÉM DO SOM
}

\section{Annita Costa Malufe SILVIO FERRAZ}

\section{Resumo}

O presente artigo busca, a partir daquilo que o compositor Luciano Berio chamou de "musicalidade presente nas livres partículas" e do estudo da trajetória do conceito de escuta, e consequentemente de música, ao longo do século XX, evidenciar um tipo de musicalidade que estaria presente em certos modos de manifestação da literatura. Para tanto, toma por ponto de partida as propostas da música concreta e do serialismo integral, experiências radicais da música no séc. XX, como base para a leitura das poéticas de Samuel Beckett, Christophe Tarkos e Georges Aperghis. Os três autores são tomados aqui como momentos distintos, que perfazem as décadas de 1970, 80 e 90, da produção poética em sua relação direta com a arte da performance. Em cada um desses casos, tem-se diferentes modulações do trabalho com a voz, ainda que em todos possamos arriscar a presença de um traço comum: a leitura do texto que se abre à sua materialidade acústica e temporal. Tal aspecto é evidenciado pela ciclicidade com que suas escritas se valem, realçando a ideia de uma musicalidade que não se reduz à sonoridade ou ao ritmo das palavras, mas à palavra em sua completude, inserida em um campo aberto de significados, sonoridades, métrica, imagens etc. Propomos assim observar a potência vocal que atravessa a poesia, imaginando um movimento de mão dupla, de mútua interferência entre as invenções da música e da poesia no séc. XX, aquela capacidade de dizer algo - seja com palavras ou outros sons - não enunciável pelo discurso, mas pelo embate livre entre palavras, fonemas, frases.

\section{Resumé}

Pour le présent article nous essayons de mettre en lumière une certaine musicalité présente dans quelques manifestations littéraires. Notre point de départ c'est ce que le compositeur Luciano Berio a appelé "musicalité présente aux particules libres" en conjonction avec les notions "d'écoute" liées à la musique au long du XXème siècle. Ce qu'il se propose ici, donc, c'est de faire une lecture des pratiques poétiques de Samuel Beckett, Georges Aperghis et Christophe Tarkos. Les trois auteurs couvrent trois moments distincts entre les décades de 1970 et 1990 d'une production poétique qui a toujours cherché une relation directe avec l'art de la performance vocale. Chacun prend par rapport une nouvelle image de voix et on peut dire qu'ils ont un trace commun: la lecture du texte ouverte vers son image acoustique et temporelle. Pourtant, nous remarquons que cette question ne concerne pas seulement la matière sonore ou même la métrique, mais la construction des cycles en comprenant les mots dans leur complétude, comprises dans un champs ouvert de signification, de sonorité, de métrique, d'images diverses etc. Nous proposons donc d'observer la puissance vocale qui traverse la poésie, en imaginant un mouvement de double sens qui comprend les jeux mutuelles d'interférence entre les inventions musicales e poétiques du XXème siècle : cette capacité de dire - soit en mot soit en sons - le non énonçable par le discours, mais qui est présent aux embats libres entre mots, phonèmes, phrases.

\author{
Palavras-chave \\ Performance, \\ musicalidade, \\ Samuel \\ Beckett, \\ Luciano Berio, \\ voz, \\ poética.
}

\section{Mots clés \\ Performance, musicalité, Samuel Beckett, Luciano Berio, voix, poétique}


Começamos nosso texto com uma pequena frase do compositor Luciano Berio ao se referir à literatura de Samuel Beckett. Evitando definir categoricamente o que seria o musical na literatura, ou o que nos permitiria dizer que um autor como Beckett produz musicalmente, Berio simplesmente observa que: "Tal qual a música, os escritos de Beckett parecem dizer aquilo que não pode ser falado". ${ }^{1}$ Esta pequena frase é o suficiente para pensarmos modos de se conceber hoje a musicalidade na literatura. Por um lado, Berio localiza o aspecto "musical" dos escritos de Beckett na sua capacidade de dizer algo que não seria enunciável pelo discurso, pela linguagem verbal. Por outro lado, ao fazê-lo, ele aponta para uma musicalidade que não vem daquilo que a música tem como tradicional e aparentemente definitivo: a melodia, o ritmo e a sonoridade. E é então como se ele ampliasse o conceito de música e, consequentemente, de musicalidade que podemos encontrar na escrita literária.

O que Luciano Berio observa sobre Beckett se dá em um lugar distinto daquele da escuta musical tradicional e, ao mesmo tempo, distinto da escuta fenomenológica da música concreta tal qual proposta pelos franceses nos anos 1940 e 50. Berio busca falar de uma escuta musical já não mais atrelada ao reconhecimento de melodias, harmonias ou estruturas rítmicas, tal qual temos na canção, seja ela de tradição tonal, modal ou atonal. Berio observa em Beckett a presença de uma musicalidade que estaria na base desta outra: a musicalidade presente na livre combinação de partículas elementares, e não mais de melodias ou harmonias. No entanto, vale ressaltar que, por outro lado, ele também não adere à proposta concretista, que se propôs como o polo oposto da música tradicional.

Vale aqui um parênteses para realçar que, na música concreta, tal como conceituada por Pierre Schaeffer em fins da década de 1940, o compositor já não partiria das notas musicais enquanto uma convenção abstrata a ser anotada na partitura -, mas sim de sons concretos, muitas vezes preexistentes, pré-gravados e recombinados como se fossem tijolos para construção. Esses "objetos sonoros", tal como Schaeffer definia em seu Traités des objets musicaux, seriam o material da música concreta, não aceitando mais a antiga distinção entre sons e ruídos. O objeto sonoro para Schaeffer seria o som subtraído de todo juízo simbólico, resumindo, o objeto sonoro seria o som em si. É assim que Schaeffer distingue os objetos musicais - notas, acordes, melodias - do objeto sonoro, este podendo tanto compreender os sons musicais quanto os ruídos descartados da composição musical tradicional de fundamentação rítmico-melódico-harmônica. A escuta buscada por Schaeffer e pela música concreta seria aquela escuta reduzida a um suposto objeto sonoro em si. Escuta fenomenológica atada à noção de époché de Husserl, conforme a leitura de Schaeffer.

De onde então Luciano Berio estaria falando? Foi comum à geração pós-guerra a composição vocal em que o menor elemento composicional estivesse no fonema. Seguindo a tradição serial que havia reduzido o objeto musical ${ }^{2}$ à nota, a seus parâmetros primários (altura, duração, intensidade, timbre), os compositores encontraram na fonética uma base semelhante para chegar-se aos parâmetros primários da palavra. A proposta de uma música eletrônica, de sons sintetizados, realizada por Werner Meyer-Eppler nos estúdios da Rádio de Colônia, ${ }^{3}$ e seus estudos sobre a síntese de voz humana por meio de recursos da eletrônica, encontrou no fonema, nos formantes de vogais, nos ruídos transientes das consoantes, os elementos para esta parametrização. Desse modo, se a música se aproximou da materialidade do som através da música concreta, ela também se aproximou das entranhas do som através da música eletrônica alemã, duas visões bastante distintas no que diz respeito ao objeto sonoro. Se Schaeffer montou 
a música concreta sobre uma escuta fenomenológica, Meyer-Eppler, Karlheinz Stockhausen, Herbert Heimert e Gottfried Michael Koening, pensaram sua música com vistas à síntese do som. Esta visão do grupo de Colônia levou-os à exploração não do som em si, mas de seus parâmetros primários visando a síntese de novos sons.

É então neste sentido que devemos compreender a proposição de Luciano Berio ao falar da música em Beckett. Berio não se vale do conceito tradicional de música - dos objetos musicais -, tampouco da noção de objeto sonoro. A música em Beckett não estaria assim restrita nem à presença do som, nem à de uma estrutura ritmo-melódica. Tal qual o próprio Berio realiza na composição de suas obras vocais como Sequenza III para voz ou O King, ao explorar a sonoridade das palavras através da manipulações de suas bases fonéticas, visando a síntese de novas palavras e novos sons vocais, em Beckett esta síntese teria na palavra, não redutível a sua sonoridade, a base para a síntese de um poema, a síntese de um texto ainda não significante. Estaríamos diante, de certo modo, daquilo que Michaux chamou de uma língua nascente ${ }^{4}$ pois, ao compreender a música em Beckett, Berio não separa significante e significado; para ele, cada palavra continua atada à cadeia de significados que dispara, e que ao mudar de posição em um enunciado sempre dispara cadeias diferentes, intercambiando regimes semióticos. Para Berio, cada palavra seria a menor peça deste móbile que Beckett realiza, e que em muito se aproxima à prática composicional do serialismo dos final dos anos 1950 e início dos anos 1960, na obra de compositores como o próprio Berio, como Gÿorgy Ligeti, Henri Pousseur, Luigi Nono e Karlheinz Stockhausen. Ou seja, um serialismo em que o menor elemento não é apenas aqueles parâmetros primários da nota musical (altura, intensidade, duração e timbre), mas estaria ampliado à formantes proto-melódicos, rítmicos, articulados como amostras sem descartar seus significados primeiros, mas ao mesmo tempo o desfazendo ao permitir novas conexões entre tais formantes. ${ }^{5}$ É esta prática que vemos transposta para a escrita em que os parâmetros elementares deixam de ser apenas os fonemas (definidos pelo seu conteúdo espectral, ruído, impulso e pulsação), ${ }^{6}$ passando a implicar também amostras sonoras de maior duração, no nosso caso as palavras e enunciados, tomados sempre como amostras autônomas, que se conectam de modo distinto daquele da sintaxe tradicional.

É deste lugar que Berio parece falar de Beckett, ou seja: não se trata de descer às partículas elementares da fala ou da voz, indo além da palavra para escrever, isto é: não se trata de descer às partículas pertinentes ao campo fonético de cada componente de um texto ou fala, por exemplo. Nem se trata de permanecer atado à sonoridade das palavras. É deste modo que a busca por elementos mínimos para se compor e escrever não equivale aqui a desmontar a palavra empiricamente, a ponto que ela deixe de ser palavra e se decomponha em fonemas. Esta visão distingue assim o que Beckett estaria propondo daquilo que havia sido proposto pela poesia sonora atada ao som, e em prática desde os futuristas. O que Berio vê em Beckett é justamente o recombinar livre das palavras em sua completude, de modo a sempre aludir significados, mas significados que recombinados juntos às palavras dão a cada momento espaço para o nascimento de novas cadeias de significados, o texto dando a nascer novos textos. Ou seja, aqui a palavra não abre mão da sua camada discursiva, suas funções de designação e significação. Mas é justamente operando junto com essa camada que Beckett irá atuar para desfazer o discurso, criando novas cadeias a partir de novas combinações, novos conjuntos. 
Tal qual na música, autores como Beckett e toda uma corrente que segue caminhos demarcados por ele, o que não pode ser dito com as palavras é justamente aquilo que cada palavra individualmente não poderia compreender por si só; e é, ainda, aquilo que as sintaxes tradicionais, isoladas, não conseguiriam alcançar, uma vez que se bastam em formas por demais estáveis.

É o próprio Berio que, em sua entrevista sobre Beckett, nos dá ainda mais uma chave para pensarmos este domínio de criação em que matéria e forma são inventadas, ao invés de serem simplesmente retomadas: "Tal qual na música, é possível haver uma enorme distância fenomenológica entre os menores detalhes factuais e o design obscuro e poético de Beckett" (p. 189). Berio alude às exaustivas descrições de detalhes feitas por Beckett, que podem ser de espaços milimetricamente mapeados, como em Le dépleupler, ou gestos obsessivamente explorados e narrados, como por exemplo em Comment c'est ou nos romances da trilogia do pós-guerra, Molloy, Malone meurt e L'Innommable. Descrições obsessivas que são presentes em muitos textos de Beckett, não apenas nesses, e que ao mesmo tempo coexistem com um contorno geral da obra que prescinde desses detalhes individuais. Como se os pequenos percursos locais, as inversões e repetições de termos, as expressões permutadas, as brincadeiras com detalhes minúsculos apenas apontassem falsos caminhos, que não levam a lugar algum. Assim como o falatório das personagens que, tantas vezes, são falatórios sem finalidade para além daquela de apenas falar e falar, dizendo algo que não seria encontrável no campo geral da significação. É o que faz Berio falar em falsas narrativas beckettianas, em que ocorre essa disjunção entre os pequenos percursos locais, e sua extrema precisão quase matemática, e a forma final do todo da obra, que guarda toda uma atmosfera obscura e de indeterminação, muito distante da aparente exatidão dos detalhes em particular.

As vozes narrativas surgem como que nascidas da permutação, da operação de conectar as palavras em frases e mudá-las de lugar, fazendo com que transitem de uma frase à outra ou mudando de lugar dentro da frase e, ainda, transitando pelo texto como pequenos motes. Neste sentido, Worstward Ho (de 1983), uma das obras finais de Beckett, é exemplar, composta do início ao fim com um número restrito de palavras, que se arranjam em orações curtas e muitas vezes repetidas, ou retomadas com pequenas inversões ou variações. Os termos que compõem o início do texto, por exemplo -"On. Say on. Be said on. Somehow on. Till nohow on. Said nohow on." adiante: "On. Stare on. Say on. Be on. Somehow on. Anyhow on. Till dim gone. At long last gone. All at long last gone". ${ }^{8}$ E na página seguinte: "On. Somehow on. Anyhow on. Say all gone. So on. In the skull all gone. All? No. All cannot go. Till dim go". ${ }^{9}$ Pequenos segmentos de frase bastante aproximados, compostos de palavras que funcionam como pequenas peças que são permutadas. Se olharmos nos detalhes há quase uma precisão matemática, de fato, no modo de fazer esta arte combinatória de palavras, vejamos em paralelo os seis primeiros segmentos de cada um desse excertos (grifos nossos):

$\begin{array}{llll}\text { "On. Say on. } & \text { Be said on. } & \text { Somehow on. } & \text { Till nohow on. Said nohow on." } \\ \text { "On. Stare on. } & \text { Say on. } & \text { Be on. } & \text { Somehow on. Anyhow on." } \\ \text { "On. Somehow on. } & \text { Anyhow on. } & \text { Say all gone. } & \text { So on.In the skull all gone." }\end{array}$


No caso de Worstward Ho, o "on" é um dos termos mais recorrentes, voltando associado a diferentes palavras e ocupando diferentes posições na sentença. Ele funciona como um dos motes do texto também, pontuando ritmicamente a leitura, como vemos nesses três trechos exemplificados. É desta operação elementar de repetição e permutação que nascem cenas, situações, modos de fala, que se abrem para muito além do jogo aparente de mudanças de posições em uma estrutura.

Notemos que, em Beckett, não se trata de um jogo apenas estrutural. Os deslocamentos, revezamentos de palavras desembocam em situações e enunciados que em pouco refletem as operações que o dispararam. Não se trata de evidenciar uma estrutura, ao contrário. $\mathrm{O}$ deslocamento dos elementos na estrutura tem como efeito principal o embaralhamento da significação e o ofuscamento da forma, servindo mais ao efeito de obscuridade (como define Berio) do que à explicitação de sua construção formal. É neste sentido que Berio nos diz que em Beckett a camada de significado em pouco reflete as operações de base. Há um contorno geral, uma atmosfera que se destaca, como se saltasse dos detalhes locais, construindo efeitos para além deles. Se há um sentido na camada notável do que se ouve, esse não se refere à estrutura, seria antes como que essa atmosfera geral, que acontece como efeito na leitura do texto. Poderíamos nos valer aqui de uma imagem de Deleuze, que define o sentido como um "vapor", um efeito incorporal que se eleva da camada empírica, dos corpos, extrapolando a pura materialidade fenomenológica. Um efeito que é disparado pelos corpos e que a eles afeta. E, ainda, um efeito que possuiria nos corpos uma quase-causa, não podendo ser direta ou previsivelmente dedutível dos estados de coisa (cf. Lógica do sentido, em especial nas primeiras cinco séries do livro).

Se por um lado a poesia no século XX bebeu de toda a novidade trazida pela música concreta, das inovações proporcionadas pelo microfone; se ela pode se valer dos detalhes sonoros da voz revelados pela mecânica da gravação e da amplificação sonora, ela não se bastou neste que foi o primeiro passo, o passo da poesia sonora: explorar as sonoridades reveladas pelo alto-falante e o gravador. E assim, a vasta exploração de loops, ecos, reverberações, ruídos e mudanças de entonação, desmembramento de palavras ou frases com ou sem sua reiteração, acelerações e retardamentos, entre outros recursos que tanto marcaram as experiências da primeira geração de poetas sonoros do pós-guerra, foram o primeiro instante de algo que irá além, em direção a outro conceito de musicalidade. Nesse primeiro momento, que também se relaciona à invenção da música concreta e da música eletrônica, tem-se inventores como Bernard Heidsieck (1928), produzindo até hoje performances e seus livros acompanhados de gravações, o inglês (que viveu em Paris) Brian Gysin (1916-1986), com seus "permutational poems"; ou Henry Chopin (1922-2008), e os "áudio-poemas" e as experimentações com a própria materialidade da voz, que Heidsieck via um "virtuosismo bucoinstrumental"; ${ }^{10}$ e, ainda, um precursor como François Dufrêne (1930-1982), com seus filmes e poemas sonoros, operando uma radical desconstrução da palavra em partículas sonoras.

São exemplos dos inventores que deram este primeiro passo. Mas depois, tanto no campo da música quanto da literatura, abrem-se práticas distintas da poesia sonora e da música concreta, tendo como foco composicional o investimento em procedimentos relacionáveis à voz enquanto fala, aos fluxos de pensamento, ampliando essas experiências bem como aquelas que já se via nos escritos surrealistas ou em uma literatura como a de Gertrude Stein ou Charles 
Péguy - esses últimos trabalhando cada um a seu modo o procedimento de repetição. Parecenos ser este o caso de Beckett, que na década de 1950 escreveu sua trilogia, que culmina em $O$ inominável, que propõe o trabalho com o fluxo vocal já em termos que nos parece extrapolar a voz como som. Até mesmo um poeta como Ghérasim Luca, mais lembrado por sua prática de poesia sonora em um sentido estrito, realiza um passo em que as palavras são recombinadas e repetidas como se fossem elementos soltos, dos quais o som é somente uma das facetas. As palavras são tratadas como elementos físicos, materiais, que ao se combinarem podem construir gestos vocais, que vão além de sua camada sonora. A voz como fluxo rítmico de movimentos, já não restritos ao fenômeno do som.

Algumas experiências do próprio Bernard Heidsieck parecem propor algo neste sentido, levando adiante o caráter centrado no som da poesia sonora; é o caso de alguns de seus "poemas-partituras" (poèmes-partitions), que concebem uma partitura para voz em que o que está em jogo é sobretudo o fluxo rítmico e a curva de movimentos que pode ser criada entre o texto, roteiro gráfico de forças, e sua leitura. Por exemplo, em seu Poème-partition $V$ (de 1956), que ele diz ser V de Varèse e V de "vite" (veloz), a velocidade de dicção do poema é parte integrante do texto, como diz Bobillot em seu estudo sobre Heidsieck, ${ }^{11}$ a performance inclui-se na própria inscrição do poema, independentemente se ele será ou não executado em voz alta. Neste ponto, notamos que a performance que aí se implica não necessariamente se refere ao som audível, mas refere-se antes de tudo ao ritmo, ao movimento, que pode ser algo performado inclusive em silêncio. E que, na proposta de Heidsieck, localiza-se na questão da ação: mais do que sonoro, o poema tem de ser para ele ação, movimento e imersão de um corpo no espaço. Por trás de sua áudio-escrita, o que se delineia é a ideia de um poema como presença, do corpo, da voz, do gesto, e imersão na objetividade das coisas. ${ }^{12}$ Imersão que se faz através do ritmo.

Neste sentido, vale evocarmos livros do poeta-pintor Henry Michaux, que em Par des traits e Par la voie de rythmes ${ }^{13}$ realiza poemas-imagens com traços e manchas de tinta que se movem segundo ciclos rítmicos. O trabalho que Michaux realiza aqui remete diretamente a um entrecruzamento dos sentidos. O que experimentamos aí é um ritmo que, vez por outra, mesmo sem palavras, nos faz "ouvir com os olhos", ou mesmo seguir uma dança de manchas que estariam estáticas no papel. ${ }^{14} \mathrm{O}$ fato é que, a partir do ritmo tomado como uma força, e portanto um fator que se dá para além das domínios empíricos, temos a possibilidade de conceber uma musicalidade e uma vocalidade que se destacam da categoria do sonoro. Trata-se aqui de um ritmo intensivo. É o que propõe Deleuze ao falar da sensação na obra do pintor Francis Bacon, conceituando o ritmo como essa força multissensível, uma "potência vital que extravasa todos os domínios e os atravessa". ${ }^{15}$ Parece-nos que, neste ponto, ao trabalhar com as palavras descendo à sua camada rítmica, música e literatura se aproximam não para a realização de uma literatura sonora ou de uma música do texto, mas para a realização de uma poesia-em-música ou música-em-poesia. Em que a musicalidade se define para além da própria sonoridade, ou de uma fenomenologia do som. Lugar de encontro da potencialidades estratégicas desenvolvidas em uma arte do som (a música concreta e eletroacústica) na sua descida aos seus pontos mais elementares e de combinatória livre dos pontos da aparente superfície (as palavras). 


\section{Voz: máquina de permutação de palavras}

O caráter propriamente "musical" da prosa beckettiana viria, para Berio, de um falar por falar, momento em que a fala - e portanto a voz - se autonomiza. Torna-se ela mesma um personagem:

(...) há uma coisa que é peculiarmente e 'beckettianamente' musical: é o fato de que, a maior parte do tempo, esses pseudo-personagens de Beckett (de $O$ inominável, Fim de partida, A última gravação de Krapp etc.) não sabem com quem estão falando: com eles mesmos? Conosco? Com outro pseudo-personagem? Com um público? Eles nem mesmo sabem sobre o que estão de fato falando. ${ }^{16}$

Ou seja, não está em questão o sobre "o que" se fala, mas sim, o próprio ato ou gesto de falar, que passa a valer por si mesmo. A voz neste caso não fala "sobre" algo: ela apenas fala. Não à toa, figuram na obra de Beckett vozes sem origem: vozes em off, que vêm de um lugar incerto ou que saem de gravadores (sendo emblemática a peça Krapp's last tape, de 1958), ou vozes que saem de cabeças (em diversos textos, e exemplarmente nas três cabeças de Play), tímpanos ( $O$ inominável) ou bocas (a boca autonomizada flutuando no palco escuro em Not $I$ ), como partes destacadas de um corpo ou personagem. Vozes que falam para além de um suporte, seja ele o corpo ou o sujeito que lhe dariam origem. Essas vozes sem origem, tornadas autônomas, seriam típicas de um certo drama moderno, no qual o cinema serve também de inspiração - e de que Beckett costuma ser um dos exemplos privilegiados tanto de Hans-Thies Lehmann, ao se referir ao que chamou de teatro pós-dramático, quanto do diretor francês JeanPierre Sarrazac, ao criar com seu grupo de pesquisa o Léxico do drama moderno $e$ contemporâneo. ${ }^{17}$ A polifonia em Bakhtin é evocada por Sarrazac, ao falar da proliferação vocal que ocorreria nesses textos, desfazendo a identidade dos personagens, desatando a voz do sujeito psicológico e colocando em primeiro plano a multiplicidade de vozes que compõe qualquer voz. A teatralidade é aqui fundada na oralidade, no sentido de uma exploração da escuta de vozes; dramas tomados por uma "poética da voz" 18 que caracterizaria esse novo drama. Para Lehmann, ainda que em outros termos, o novo teatro redescobriria a voz, separando-a dos significados e das fontes emissoras (o que se intensifica com o uso da tecnologia) e fazendo assim emergir "vozes sem lugar" ou "vozes em suspenso". ${ }^{19}$

Neste contexto de exploração da vocalidade, cabe salientar que mesmo Sarrazac se refere a dois modos de se conceber essa voz no novo drama. O primeiro que seria mais ligado a sua empiricidade, a exploração dos potenciais físicos da voz no palco pelos atores (fonéticos, timbrísticos...) e o segundo - próximo ao que nos interessa aqui - ligado ao que ele chama de uma "voz dramatúrgica ou poética", que vigora nos textos dramáticos enquanto potencialidade de encenação. ${ }^{20}$ Neste sentido as vozes sem lugar que emergem na encenação remetem diretamente a essas vozes sem lugar que conduzem o texto. Isto nos interessa para localizarmos essa voz enquanto potência que se dissemina no próprio texto e que extrapola o dado empírico. A voz se torna ela mesma um personagem, torna-se ao mesmo tempo sujeito e objeto de um fluxo que muitas vezes não narra nada além do que seu próprio percurso de voz, dizendo-se e compondo-se enquanto fluxo vocal em perpétuo movimento. Movimento este de reiterações, retomadas, hesitações e sobretudo permutações.

Diríamos que o que ocorre nesse tipo de experiência é que a voz do texto se torna uma máquina de permutação de palavras que, tal qual na música serial, faz nascer o texto literário a 
partir da mistura inusitada de elementos, reinventando sintaxe e forçando as palavras a se conectarem livremente. Fazendo assim com que, na camada mais externa, reste-se muito pouco dos traços do movimento das menores partículas - conforme o que Berio enxerga na dinâmica do texto beckettiano. A voz, essa máquina de permutação, cria um fluxo sonoro, um envelope de palavras, onde ela é o lugar das possibilidades sonoras, hábitos de fala, tiques, manias, que moldam os fluxos. Ou seja, a operação de fundo, a permutação das palavras, se dá a partir de hábitos, recorrências, que são antes de tudo corporais; e se há algo de sonoro que salta em uma poesia ou prosa de tradição beckettiana, este sonoro não é primeiro, mas apenas salta como esse lugar em que as permutações se dão.

Será na esteira desta proposta de Beckett, tal qual localizada por Berio, que encontraremos toda uma tradição de escrita poética que se apoia na permutação livre de termos, sempre circunscritos a hábitos de fala, atrelados a uma voz falante. Máquina que não apenas reitera palavras, frases, mas que as seleciona, assim como opta pelos modos de combiná-las. Tal qual se reconhece um som como sendo de um ou outro instrumento musical, independente de quem está tocando, reconhece-se também a voz sempre como sendo "voz", som de voz, independentemente de quem fala, de seu timbre e trejeitos. E, do mesmo modo que não é apenas o timbre que define um instrumento, mas todo um conjunto de gestos e predisposições musculares e adaptações ergonômicas, não é apenas o timbre que define uma voz mas todo um conjunto de hábitos vocais. Podemos pensar que esses hábitos da voz dizem respeito a predisposições genéticas, formato de rosto, tiques, manias musculares, hábitos de significação, hábitos culturais e familiares, imagens recorrentes, incontáveis aprendizados tidos em diferentes momentos e selecionados, descartados, reiterados. Hábitos que incluem, ainda, diferentes velocidades: desde aquela de conexão entre as significações e imagens que são trazidas pelas palavras até a velocidade de dicção, de correr mais ou menos de uma sílaba a outra, mais ou menos de uma palavra a outra, pausar mais ou menos entre as frases e assim por diante.

Concebida dessa forma, a voz é reconhecível mesmo se não a ouvimos empiricamente, ou seja, mesmo se não captada pelo sentido da audição. A voz é algo que podemos grafar sem que deixe de ser voz. Daí nossa possibilidade de, definindo-a como essa máquina de permutação de palavras que produz a cada vez um invólucro singular, pensarmos numa indistinção entre o oral e o escrito. Pensamos assim em uma voz da escrita, para além das definições atadas à fenomenologia. Mesmo na escrita mantém-se os traços de hábitos vocais, de prontidão vocal para um ou outro fonema, para uma ou outra palavra, sem que seja necessária a palavra ser pronunciada. Neste caso, tal qual encontramos em Beckett, não se trata do som da palavra como base para a construção poética, mas de uma poética construída a partir da ideia de hábitos e vícios de articulação vocal, ora encadeados passo-a-passo (em proximidade) ora por saltos, que por sua vez também evidenciam o passo-a-passo. ${ }^{21}$

Dentre os autores contemporâneos que trabalham em tal domínio, destacaríamos, ao lado de Beckett, um compositor, o grego Georges Aperghis, e um poeta, o francês Christophe Tarkos. Em ambos podemos notar a importância da repetição de palavras e frases enquanto procedimento composicional. Sendo que, em cada um, encontraríamos modos distintos de empregar a repetição e utilizá-la como procedimento que alude a gestos vocais. 
No caso de Georges Aperghis, bastante conhecido por realizar o que ele mesmo chama de um teatro musical, trata-se de um compositor que é ao mesmo tempo poeta e, muitas vezes, escreve os textos de suas composições. Pode-se encontrar uma inspiração beckettiana no seu estilo - e, corroborando com esta constatação, vale observar que sua última peça, recémapresentada em Paris (julho de 2014), Un temps bis, baseia-se em três textos de Beckett, os breves Bing e Pour finir encore e os pequenos poemas de Mirlitonnades. Exemplo recorrente da produção composicional de Aperghis são as suas Récitations, conjunto de breves obras para voz, que propõem cada uma um uso vocal diferente, variando modos de dizer, sussurrado ou gritado, sílabas alongadas ou em staccato, lento ou rápido etc., ainda que com a variação de alturas, sempre jogando com a voz falada. Nessas pequenas peças o compositor fez com que da repetição de pequenas frases se desse o nascimento lento de sequências melódicas, em um processo cumulativo em que a cada repetição acresce-se um novo fragmento melódico e uma nova palavra. Não se trata de um uso retórico da repetição, o compositor não busca com suas repetições criar algum elo de convencimento ou mesmo mnemônico com seu ouvinte, mas de repetições que desenham uma estrutura rítmica bastante clara e que cresce pelo lento acúmulo, pela lenta adição de novas palavras. Compõe assim as recitações pelo processo aditivo de palavras, que montam frases de fragmento em fragmento, de momentos sem nenhum sentido a momentos com mais sentido, de momentos com sintaxe caótica e momentos com sintaxe clara, passando assim do estável aos instável constantemente.

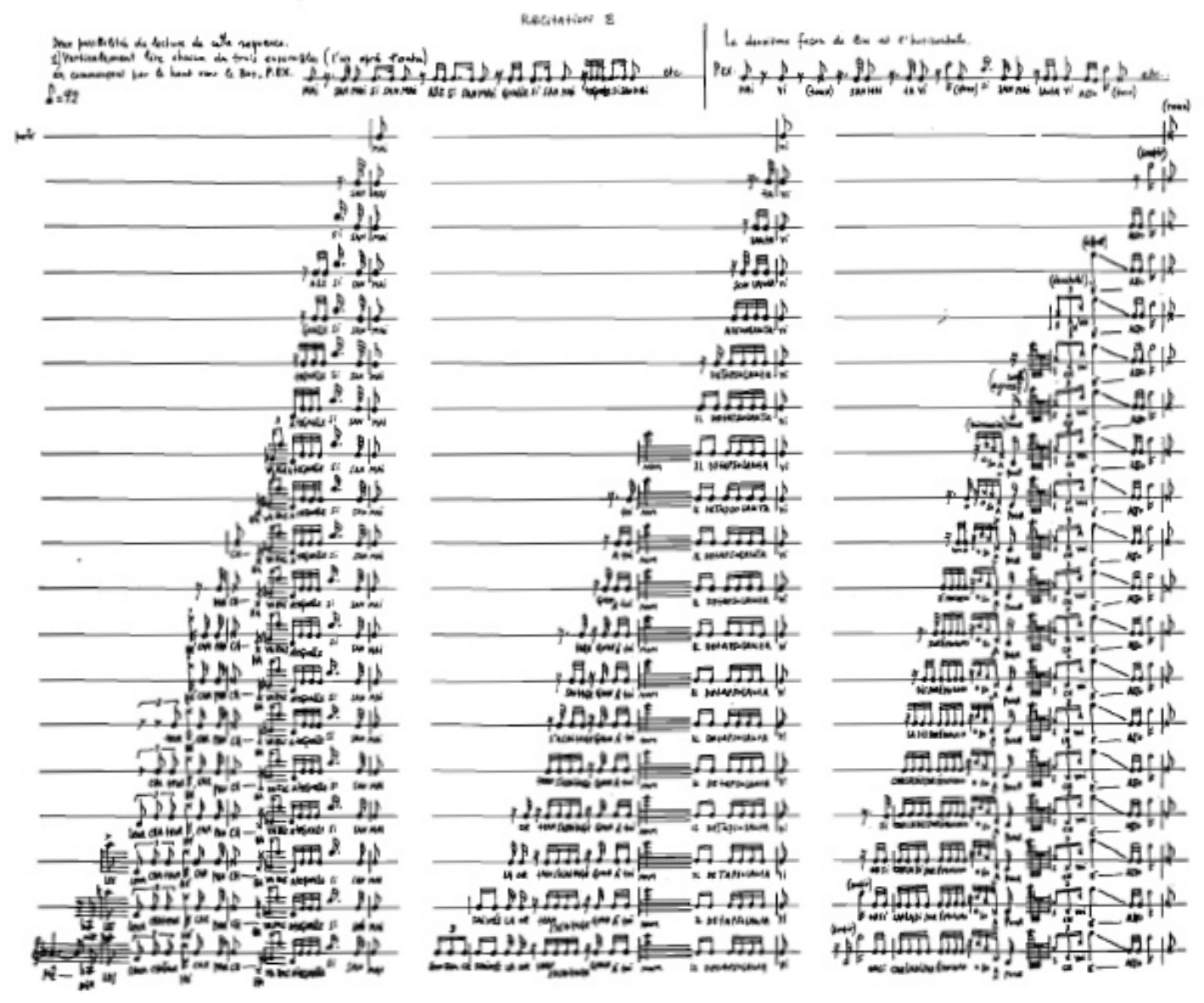




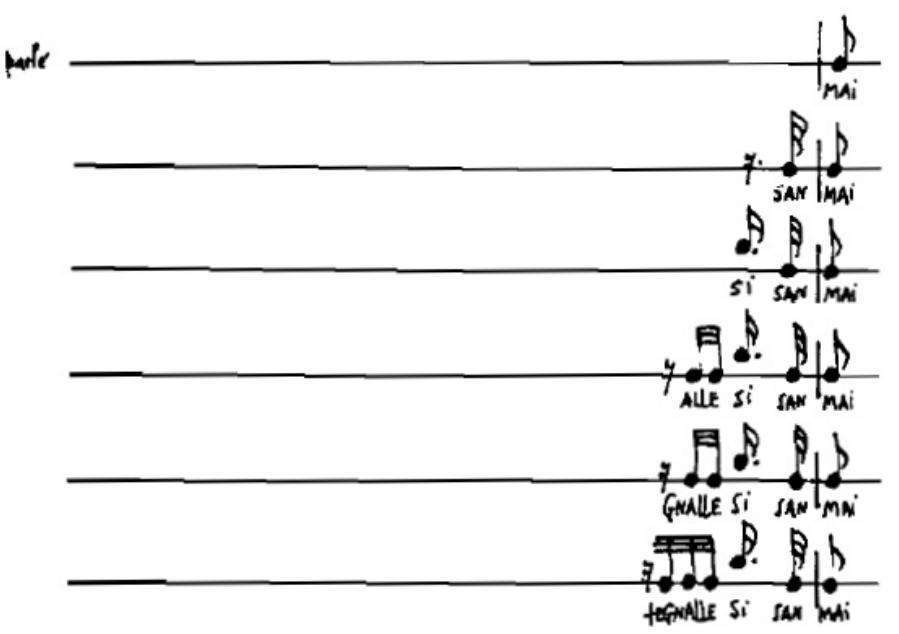

Fig. 1. Partitura de Récitation 8, a) visão geral da página, b) detalhe (Fonte: Aperghis, G. Récitations. Salabert, Paris, 1982.

Vez por outra, a composição de Aperghis vale-se do trabalho com o texto a partir de fragmentos fonéticos, lembrando o primeiro momento da música vocal serial de Luciano Berio. São momentos em que as peças, ainda que trabalhando com fragmentos de palavras, com fonemas, encaminham-se sempre para a construção de palavras, quase que retirando o foco da sonoridade que poderia estar evidente, para lançar o foco na palavra que será formada. Vale destacar que, como afirma Félix Guattari, em texto sobre a composição de Aperghis, o que sobressai é uma textura plástica de outra ordem, que atua em outra camada que não aquela do discurso, havendo aí "um modo de jogar com o não-senso em um domínio plástico que é bem diferente da tradição de jogos de não-senso dos surrealistas ou dadaístas". ${ }^{22}$ Em muitas peças, o texto participa assim da musicalidade mais ampla da obra, de modo semelhante ao que Berio dizia enxergar nos textos de Beckett. E o que salientaríamos de parentesco com o estilo beckettiano, mais uma vez, seria o fato de que os significados aqui são locais, e surgem de modo breve, tomando forma e logo se desfazendo, como se apresentassem uma significação frágil, em metaestabilidade.

Tal modo composicional, por repetições e adições de frases ou palavras, sem uma redução ao timbre da palavra ou do fonema, remete claramente a Berio que no terceiro movimento de sua Sinfonia traz textos de dois autores, Samuel Beckett, em O inominável, e Lévi-Strauss, com passagens de Le Cru et le Cuit, tratando o texto de Strauss tal qual Beckett escreve seu livro. A realização de Berio retoma trechos da versão em inglês de Beckett, The Unnamable, tradução realizada pelo próprio autor: "I must not forgot this, I have not forgotten it. But I must have said this before, since I say it now". Berio toma a fórmula de reiterações e expansões presente em Beckett e reescreve assim o texto de Levi-Strauss: "il y avait sang Il y avait il y avait il y avait une fois un indien marié et père de plusieurs fils adultes, à l'exception du dernier né qui s'appelait Assaré. Un jour, un jour que cet indien était à la chasse, les frères, les frères".

Vale citar aqui "Chansonbette", da série Récitations de Aperghis, em que a frase vai lentamente se construindo por acúmulo e reiteração: “de de mon de mon cer son de mon cer vo son de mon cer vo le son de mon cer vo vé le son de mon cervo qui vé le son de mon cervo qui grin trou vé le son de mon cerveau qui grin trou vé le son de mon cervo qui grin ce gé trou vé le son de mon cer vo qui grin ce". Poema que lentamente constrói a frase: "j'ai trouvé le son de mon cerveau qui grince". 
De certo modo, Aperghis está ligado a Berio, tanto ao processo de texto gerado passo a passo quanto ao de um texto gerado a partir de seus fragmentos não significantes, como os fonemas combinados e recombinados em $O$ King, em uma construção linear, que em Berio culmina na frase "Oh! Marthin Luther King", citado por David Osmond Smith em seu livro sobre a Sinfonia de Berio.

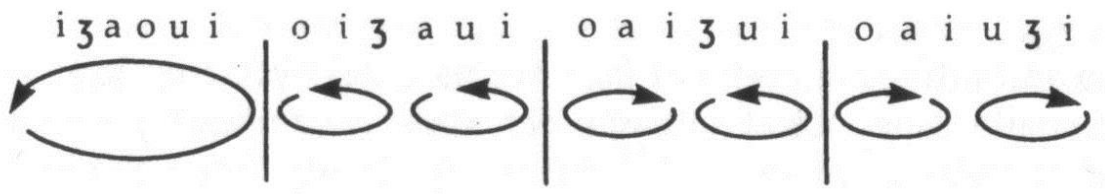

Fig. 2. Série fonética progressiva extraída da frase 0 Martin Luther King, empregada por Luciano Berio em 0 King (Fonte:

Osmond-Smith, 1991, p.36).

Há um movimento próximo ao que encontramos em alguns poemas de Ghérasim Luca, de modo mais claro em "Passionnément", poema citado por Deleuze em seu artigo “Gaguejou...' de Crítica e clínica, ao referir-se à gagueira como mecanismo de construção de uma língua poética. Luca parte de uma sílaba, "pa", repetida algumas vezes, como quem gagueja ao tentar dizer algo, para ir lentamente acrescentando, em meio a volteios e dispersões, outras sílabas que lentamente vão compondo palavras. O caminho até chegar ao final do poema à palavra do título, "passionément", é cheio de desvios, em que Luca usa do humor, para ir traçando um percurso de busca da para frase final, como em um ápice: "Je t'aime passionnément”. Vejamos os trechos inicial e final do poema:

\section{PASSIONNÉMENT}

pas pas paspaspas pas

pasppas ppas pas paspas

le pas pas le faux pas le pas

paspaspas le pas le mau

le mauve le mauvais pas

paspas pas le pas le papa

le mauvais papa le mauve le pas

paspas passe paspaspasse

passe passe il passe il pas pas

il passe le pas du pas du pape

du pape sur le pape du pas du passe

passepasse passi le sur le

(...)

je t'ai je terri terrible passio je

je je t'aime

je t'aime je t'ai je

t'aime aime aime je t'aime

passionné é aime je

t'aime passioném

je t'aime 


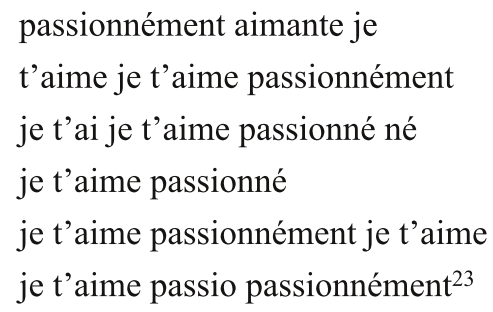

Como se vê, a partir das sílabas e da paulatina montagem de palavras que se armam e em seguida se desarmam e derivam para outras, Luca faz ao mesmo tempo uma brincadeira sonora e gestual com a linguagem. Deleuze aí enxergou uma espécie de gênese de uma língua, que se faria a partir dessas repetições - que ele denominou de uma gagueira criadora. Poeta sonoro, que participou ativamente da produção da poesia sonora, Luca gravava seus poemas e fazia performances públicas. Na gravação de "Passionnément" sua voz vai em um crescendo de velocidade e volume até explodir no grito final. Nesse poema a proposta é que o gaguejamento, a estratégia de repetição, brinque com a ideia de uma voz que titubeia, desliza, refreia, hesita e se esforça para chegar em uma frase que, de algum modo, a despeito de toda simplicidade e obviedade, traz consigo uma resistência a ser pronunciada. Ela surge ao final, assim, quase como uma explosão. Ainda que aqui a prevalência seja a do som, aparentemente, o que se joga é a dinâmica de adição que, por desvios e volteios, se completa até chegar a uma frase final. Ou seja, há um gesto vocal que aqui se constrói, envelopado por uma voz.

\section{Ciclos e derivas}

Podemos observar que tais exemplos são de um procedimento de repetição que se vale de um movimento linear, ou seja, que trabalha por acréscimos até cumprir uma espécie de ciclo de significados, ainda que esses sejam locais e breves, sem compromisso com uma significação totalizante. Poderíamos recorrer a uma outra linha de trabalho com a voz, enquanto essa máquina de permutação de palavras, em que o movimento do invólucro vocal ao invés de ser linear apresenta um movimento de deriva. Ou seja, um movimento não direcional. É este tipo de repetição por deriva que mais frequentemente encontramos nas obras de Beckett e que permeia também a obra poética de Cristophe Tarkos. A repetição é o próprio movimento de L'Innommable, se o tomarmos como um ponto de inflexão importante da obra de Beckett, a partir do qual a voz emancipada, autonomizada, torna-se mais explícita. O texto se desenvolve pela formação de eixos provisórios - que podem ser temáticos ou sonoros, imagéticos... - em torno dos quais ocorrem as repetições e os encadeamentos de palavras até que um novo centro se institua e novas repetições se deem ao seu redor. E não há uma direcionalidade para a escolha desses eixos, eles surgem como que convocados pelo acaso da fala daquela voz em que o texto se encarna, a voz que narra. É uma escrita toda feita de pequenos ciclos que possuem entre si um movimento de deriva, sem qualquer linearidade ou relação de causa-efeito.

Mesmo em um poema como "Comment dire" o acréscimo de palavras, que também existe, acaba sendo aparente, ou sobreposto por um movimento que não atinge exatamente um ápice - como ocorreria por exemplo em Ghérasim Luca em que todo o poema desemboca na frase "Je t'aime passionnément" ou o de Aperghis, culminando na frase "j'ai trouvé le son de 
mon cerveau qui grince" e de Berio, "Oh! Martin Luther King". O poema também se desenvolve por ciclos, aqui menores, que são criados em torno de palavras que se revezam na função de eixo das repetições. Trecho inicial do poema de Beckett:

\author{
COMMENT DIRE \\ folie - \\ folie que de - \\ que de - \\ comment dire - \\ folie que de ce - \\ depuis - \\ folie depuis ce - \\ donné - \\ folie donné ce que de - \\ $\mathrm{vu}-$ \\ folie vu ce - \\ ce - \\ comment dire $-(\ldots)^{24}$
}

A frase parece crescer pelo meio - essa é uma das leituras que Deleuze faz do poema de Beckett, no ensaio integralmente a ele dedicado, "L'Épuisé" -, ela é crivada com esses travessões que parecem intensificar a imagem da ruptura. E a todo tempo o mote "comment dire" retorna. E será ele mesmo, ao final, a fechar o poema. O movimento indica ao mesmo tempo a deriva e o caráter de passagem, que bem descreve muitos textos em prosa ou mesmo dramáticos de Beckett. Um movimento que parece estar sempre "no meio" do caminho, sem começo ou fim. O texto começa pelo meio e é largado ao meio, sem resolução ou ponto final. Como diz o final de $O$ inominável: "é preciso continuar, não posso continuar, vou continuar". ${ }^{25}$ Estranho modo de se finalizar uma história.

Este mesmo procedimento de deriva está na poesia-prosa de Cristophe Tarkos, da qual destacamos aqui três momentos dos longos blocos de textos que compõem Anachronisme:

Il abonde, accélère, aboie, actionne, accumule, affole, aère, agresse, affronte, alterne, amalgame, amasse, agglutine, amorce, ameute, appelle, approche, articule, arrose, attente, attaque, attise, aventure, bafoue, bâillonne, balade, baratine $(. . .)^{26}$

ou, na sequência deste bloco,

Quel est le dessin laissé par les verbes, par les verbes inscrits dans la suite, par tous les événements? Tous les verbes, tous les événements, tombent, glissent, se mettent à leur place, trouvent une passe, donne un dessin, cela me donne une figure, je ne suis pas absent, cela forme, le tri, une figure de moi, la meilleure figure de ce que je suis $(\ldots)^{27}$

ou ainda, em outro bloco,

Je crois que l'on peut comprendre, il faut croire que l'on peut comprendre, que l'on peut dessiner, voilà dessiner un dessin qui démontre exactement comment ça se 
produit, une carte, un schéma, un croquis pour dire comment ça se passe exactement, en croyant que ça se passe comme ça, comme il est dessiné sur le dessin, que croire est croire que le dessin montre ce que l'on ne peut pas voir $(\ldots)^{28}$

O fluxo de voz é trabalhado por Tarkos numa deriva curiosa, em que a repetição funciona criando pequenos eixos que garantem um falso movimento centrípeto. A repetição da mesma palavra ou da mesma construção da frase não assegura o retorno ao eixo, mas a cada repetição o eixo se desloca, proliferando significados e derivações possíveis para o mesmo termo ou expressão. Ainda que Tarkos dissesse que a repetição teria para ele uma função de memória - o poeta sofreu uma doença no cérebro que o levou à morte prematura e que prejudicava em muito sua memória -, é curioso ver como a dinâmica repetitiva assumia um caráter de fluxo contínuo em sua poética da voz. Tarkos, poeta e performer de seus poemas, muitas vezes criados em improvisações em público, trabalhou a voz como seu material primeiro, numa indistinção entre oral e escrito. A língua, dizia, é uma massa de palavras, não há palavras sozinhas, isoladas, mas apenas essa "pasta-palavra" [pâte-mot], à qual moldamos segundo nosso corpo, nossos hábitos, nossos desejos. Dizia: "não há palavras sós, as palavras estão em grupo, elas se misturam em um grupo, o que faz o elemento do sentido não é mais a palavra é o grupo de palavras fundidas". ${ }^{29} \mathrm{O}$ conceito trabalhado por ele dessa "pasta-palavra" leva-nos diretamente ao conceito de voz enquanto esse invólucro, que envelopa grupos de palavras em permutação. A permutação das palavras, a retirada destas da sintaxe tradicional, o jogo constante de recorrência (as riprese, como dissemos sobre Berio), amalgama as palavras de tal modo que qualquer tentativa de segmentação se desfaz. Ao mesmo tempo, desfeita a fácil segmentação, também desfaz-se as relações de subordinação ou ordenação das frases, abrindo o campo semântico e sintático.

Visto assim, podemos observar que Tarkos como Aperghis, e os dois como Beckett, trabalham naquele lugar em que sintaxe e palavras são dois sistemas distintos que não necessariamente se conversam. A sintaxe da repetição, por exemplo, perde seu aspecto retórico de afirmação por redundância. Pelo contrário, a redundância serve aqui como que mecanismo de abrir mais e mais as frases, fazendo-as proliferar. Frases que se reiniciam com uma mesma palavra não têm mais a função retórica de anáfora, elas não afirmam nada pois ora nascem abstratamente de um jogo permutativo, de uma permutação cíclica do tipo 1-3-5-4-2, 1-5-4-2$3,1-4-2-3-5$, ora de um jogo de ritornelos acumulativos, ora por movimentos centrífugos em que a retomada de uma palavra, sonoridade de uma palavra ou mesmo função (verbo, adverbio, adjunto..) serve como ponto de partida para derivas distintas. Ao invés de afirmar algo, elas de fato cavam um buraco no estrato retórico da língua para fazê-la gaguejar e falhar. "Falhar melhor", conforme o mote reiterado por Beckett ao longo de sua obra e em especial no já citado Worstward Ho. A falha da língua apontando falsos campos semânticos, falsos regimes significantes, mas sempre aludindo um domínio sonoro próprio da voz, próprio de hábitos de uma voz.

Aqui novamente vale lembrar Berio e seu modo de trabalhar fragmentos melódicos em suas últimas obras, também desfazendo a sintaxe corriqueira do desenvolvimento melódico escolástico que, afirmado no classicismo musical, adentrou o século $\mathrm{XX}$ como norma neoclássica - de Arnold Schoenberg ao compositor Theodor Adorno. ${ }^{30}$ Em diversas de suas obras, Luciano Berio emprega um procedimento que denominou composição por riprese, por retomadas. É esta estrutura aliterativa que Berio retoma na composição de diversas obras, perfazendo praticamente os seus últimos 30 anos de sua vida (como em Les mots sont allés 
(1976), Ricorrenze (1985) Notturno (1995). Falando sobre a composição de sua peça Notturno, Berio praticamente descreve o procedimento de escrita que atravessa os autores que aqui estamos tratando:

Figure diverse si susseguono una all'altra conservando un dettaglio comune, oppure una figura si ripete identica, anche a distanza, ma con dettagli diversi. Oppure ci sono figure che ritornano immutate. Oppure, infine, ci sono eventi irrelati. Tutto questo à distribuito su archi di tempo molto diversificati e avviene in un contesto sempre mutevole dove le figure acquistano diversi gradi di coinvolgimento, di riconoscibilità e di sopravvivenza.... Credo che il senso del discorso risieda proprio nella sua assenza. Le "parole" e le "frasi" di Notturno scivolano una nell'altra, scompaiono e ricompaiono, si guardano vicendevolmente dentro, muoiono. ${ }^{31}$

É este aspecto comum à composição musical e à composição literária que chamamos aqui de a musicalidade possível de um texto, e por conseguinte sua vocalidade: a voz não como um objeto sonoro, ou como instrumento capaz de produzir objetos sonoros, mas a voz como máquina que produz envelopes sonoros que podem tanto ser decompostos quanto recombinados, ora compondo novos envelopes, ora distinguindo envelopes e os separando, os distanciando. Cujos objetos se destacam tanto pelos envelopes que desenham, pelas curvas sonoras que desenham, quanto pelas cadeias de significados que disparam, mas que não se reduzem em nenhum momento à sua sonoridade.

A musicalidade aqui estaria neste trabalho com objetos vocais. Tal qual o compositor trabalha com objetos musicais (acordes, proto-melodias, motivos, estruturas rítmicas) e com modos de articular sonoramente tais objetos (staccato, legato, portato, pizzicato, smorzato, leggiero, sussurrato, mormorando...), a escrita verbal escreve com envelopes os colocando em ciclos. Não apenas as estruturas métricas da poesia tradicional, nem os ciclos fechados por rimas, mas estruturas pulsantes de tamanhos diferentes, que ora apressam, ora ralentam, ora suspendem o passar do tempo, em uma variação constante de velocidade. Vale lembrar que nem toda música, poesia ou prosa segue este modelo, mas que tal modo de composição aproximou música e escrita verbal a partir justamente de uma potência própria da vocalização de uma palavra, independente de sotaques ou detalhe timbrístico (como o fez a poesia sonora), que é a presença da recursividade como modo de introduzir o tempo na criação sonora.

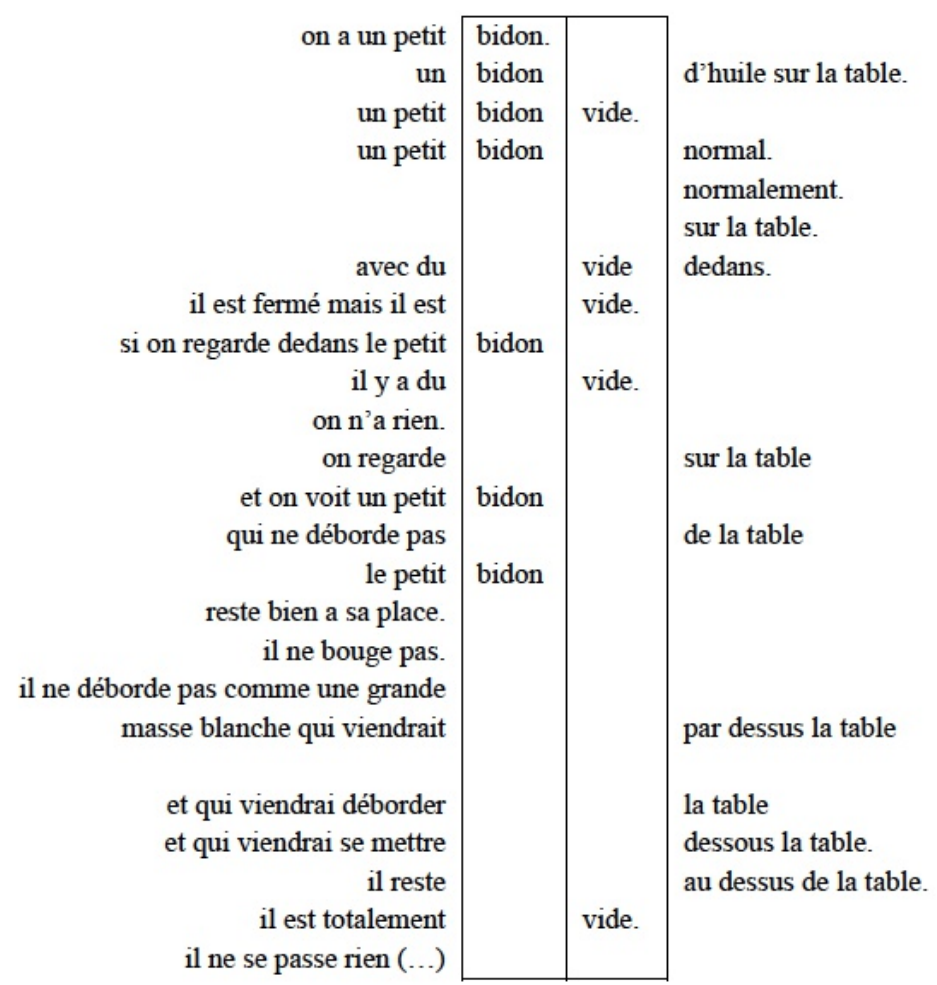



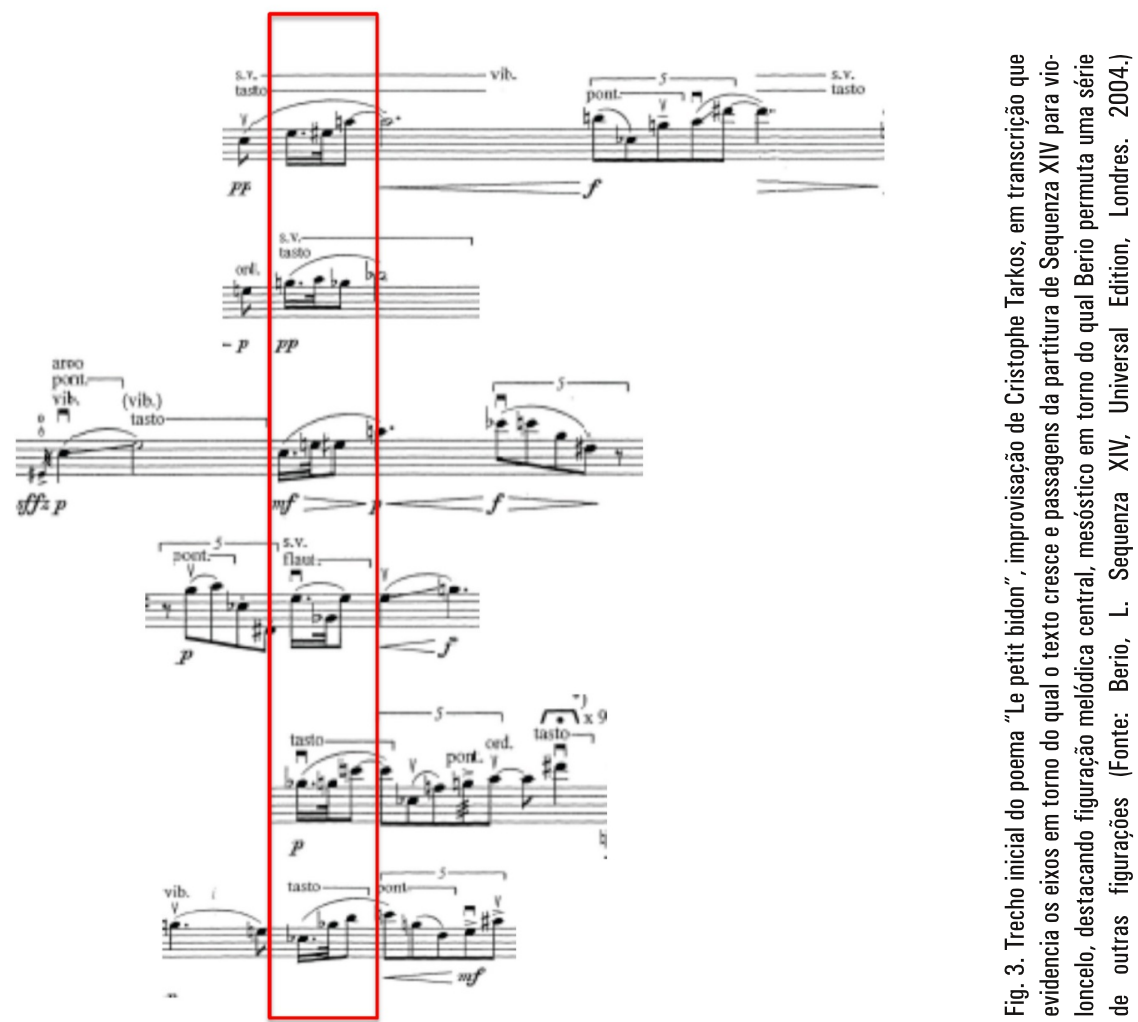

Um pequeno exemplo deste modo de trabalhar um móbile de fragmentos melódicos aparece na Sequenza XIV para violoncelo de Berio. Vale aqui a visualização desta estratégia para compreendermos sua relação com a invenção poética e musical de Tarkos. ${ }^{32}$

De certo modo, o ponto de partida aqui é a leitura que Berio realiza da poesia e da prosa beckettiana, e tal ponto de partida se dá por uma razão bastante especial. Talvez Berio, mais do que qualquer outro dos compositores da geração serial, tenha sido o compositor que compreendeu em seu processo criativo a dimensão temporal trazida pela repetição dentro da música. A repetição trabalhada não como tempo mítico, mas como afasia, as afasias da fala, o que a partir de Deleuze chamamos antes de gaguejar. A repetição se dá nesta visão de Berio como uma espécie de buraco negro do qual só se escapa com a força impulsionada por uma diferença brusca.

É neste ponto que podemos não apenas falar da poesia e prosa de Beckett mas também daquela do poeta Christophe Tarkos, que fez da repetição um de seus princípio de composição poética. E que, tal qual observamos no caminho aberto na música, por Luciano Berio, se vale da repetição não como princípio de anáfora, mas da repetição como que o uso de pequenas partículas para síntese e ressíntese de frases, cadeias melódicas e rítmicas, etc.

Como conclusão deste ensaio talvez possamos acrescentar algo a nossa premissa inicial. Ao invés de imaginar uma musicalidade que teria adentrado a escrita literária, pensar também em uma poética da voz que adentrou a música, bem como o teatro, imaginando assim um movimento de mão dupla, de mútua interferência. E daí uma potência vocal que atravessa ambas as práticas, remetendo-as entre si. De Beckett a Berio, de Aperghis a Tarkos. O que este trânsito nos permite notar é que se a musicalidade reside no fato de podermos ouvir, ler, e viver 
as palavras sem que nos remetam a um significado mas a cadeias infindáveis de imagens visuais, sonoras, táteis etc., ela não reside no entanto no limite do sonoro. Do mesmo modo a vocalidade não residiria apenas no sonoro, nem a verbalidade no significado. Mas em um dado que perpassa as práticas sonoras: a ciclicidade do som, a necessária de uma periodicidade dos ciclos para que se constitua uma permanência, um código por menor que seja.

É esta ciclicidade que vemos praticada de diversos modos, ora frases que giram em torno de uma letra, ora frases que giram em torno de uma palavra, ora a palavra se colocando ao início ora ou final, ora como em um mesóstico, como realizam Tarkos em seu poema improvisação "Le petit bidon" e Berio em sua Sequenza XIV. Vemos claramente aqui a retomada de um aspecto comum à criação poética, ainda em seu momento de plena concatenação com a melodia, que teve plenitude na lírica dos trovadores provençais de Poitieux, como ressaltou Augusto de Campos ao falar da poesia de Arnauld Daniel, ou de Martin Codax. De certo modo esta oralidade que vemos reaparecer com toda sua força na obra de Beckett, Péguy, Ghérasim, Tarkos, Aperghis e Berio, traz não a marca da sonoridade, talvez o primeiro passo deste momento (ainda com os poetas sonoros), mas a da ciclicidade. Agora uma ciclicidade não mais concêntrica, mas centrífuga, em que as repetições funcionam como núcleos generativos e não como âncoras de retorno. Os ciclos agora, ao invés de um eixo fixo, notável, se dão em torno de um atrator que muda constantemente de lugar. Tem-se assim a presença do ciclo, próprio aos recursos de recorrência da fala, mas de certo modo potencializados pela deriva. O movimento antes estável dos ciclos da tradição poética e musical, agora caem na vertigem da deriva em que são tomados os personagens de Beckett.

\section{Referências bibliográficas}

ADORNO, Theodor W.. Philosophie de la nouvelle musique (1948), trad. Hans Hildenbrand et Alex Lindenberg, Gallimard, 1962.

Quase una fantasia, Paris, Gallimard, 1963.

BeCKett, Samuel. Como é. Trad. Ana Helena Souza. São Paulo: Iluminuras, 2003 (dos originais em francês Comment c'est, 1961, e em inglês How is it, 1964). Company, Ill seen Ill said, Worstward Ho, Stirrings still. Londres: Faber and Faber, 2009. . O inominável. Trad. Ana Helena Souza. São Paulo : Globo, 2009. Poèmes, suivi de Mirlitonnades. Paris: Minuit, 1978.

BOBILlot, Jean-Pierre. Bernard Heidsieck, poésie action. Paris: Jean Michel Place, 1996.

BERIO, Luciano. "Beckett and music, an interview with Luciano Berio". In: BRYDEN, Mary (ed.). Samuel Beckett and music. Oxford: Clarendon Press, 1998. “Notturno (1995)". Scritti sulla musica. Torino: Einaudi, 2013.

DELeuze, Gilles. Critique et clinique. Paris: Minuit, 1993. Francis Bacon, logique de la sensation, Paris, Éditions de la Différence, 1982. Guattari, Félix. Mille plateaux - Capitalisme et schizophrénie 2. Paris: Minuit, 1980.

eimert, Herbert. "What is electronic music?", Die Reihe 1, Londres: Universal Edition, 1957.

ferraz, Silvio. "La formule de la ritournelle". Revue Filigrane, v.13. Paris: Maison de Science de 1'Homme Paris Nord, 2012.

GUATTARI, Félix. "L'hétérogenèse dans la création musicale”. Chimères, 1991. Disponível em : http://www.aperghis.com (acesso em dezembro 2007). 
HEIDSIECK, Bernard. Canal street. Paris: Al Dante, 2001.

Lehmann, Hans-Thies. Teatro pós-dramático. Trad. Pedro Süssekind. São Paulo: Cosac Naify, 2007. 2001.

LuCA, Ghérasim. Héros-limite, suivi de La Chant de la carpe et de Paralipomènes. Paris: Gallimard/ Poche,

MESSIAEN, O. Techniques de mon langage musical. Paris: Leduc, 1940.

MEYER-EPPLER, Werner. Elektronische Klangerzeugung: Elektronische Musik und synthetische Sprache. Bonn: Ferdinand Dümmlers, 1949. . "Statistic and psychologic problems of sound". Die Reihe 1, Londres: Universal Edition, 1957.

MichauX, Henri. Par des traits. Paris: Fata Morgana, 1984.

. Par la voie des rythmes. Paris: Fata Morgana, 1974.

oSMOND-SMith, David. Playing on words, a guide to Luciano Berio's Sinfonia. Londres: Royal Musical Association. 1985.

SARRAZAC, Jean-Pierre (org.). Léxico do drama moderno e contemporâneo. Trad. André Teles. São Paulo: Cosac Naify, 2012 (do original Lexique du drame moderne et contemporain, 2005).

SCHOEnBerg, Arnold . Fundamentos da Composição Musical. São Paulo: Edusp, 1991.

TARKos, Christophe. Anachronisme. Paris : P.O.L., 2001.

Caisses. Paris : P.O.L., 1998.

Écrits poétiques. Paris : P.O.L., 2008.

Le Signe =. Paris : P.O.L., 1999.

XENAKIS, Iannis. Musique et Architecture. Tournai: Casterman, 1971.

CD (áudio)

TARKOS, Christophe. Expressif, le petit bidon - improvisations et lectures. Paris: Cactus, 2001.

\section{Notas de fim}

${ }^{1}$ Luciano Berio, "Beckett and music, an interview with Luciano Berio", Samuel Beckett and music, 1998, p. 189.

2 Tal qual definido desde seus primeiros momentos nas composições Modes de valeurs et d'intensités (1949) de Olivier Messiaen, na Sonata para dois pianos (1950) de Goyevaertz e em Structures (1951) de Pierre Boulez, na "ars combinatória" do serialismo integral, a música não nasce com base em formas predefinidas de melodia, ritmo, harmonia ou mesmo concepção timbrística. A partir dos parâmetros elementares da nota musical (altura, intensidade, duração e timbre), os compositores agenciavam estruturas combinatórias de tais parâmetros elementares de modo a dar nascimento a formas inusitadas, sequências rítmico-melodicas não previstas pela tradição. Cadeias de sonoridades instrumentais não mais relacionáveis à tradição da orquestração homogênea que imperou no classicismo e romantismo musicais ao longo do séc. XIX.

${ }^{3}$ Meyer-Eppler, Werner, Elektronische Klangerzeugung: Elektronische Musik und synthetische Sprache, 1949.

${ }^{4}$ Henri Michaux, Par des traits, 1984.

5 Como veremos mais adiante, tal procedimento é aquele que Luciano Berio se vale em composições como Sequenza XIV, para violoncelo (ver Fig.3), ou em seu quinteto Ricorrenze.

${ }^{6}$ A este respeito, ver: Eimert, Herbert. "What is electronic music?" e Meyer-Eppler, Werner. "Statistic and psychologic problems of sound". Die Reihe 1, 1957.

${ }^{7}$ Samuel Beckett, Company, Ill seen Ill said, Worstward Ho, Stirrings still, 2009, p. 81.

${ }^{8}$ Idem, p. 90.

${ }^{9}$ Idem, p. 91

${ }^{10}$ Conforme o estudo de Jean-Pierre Bobillot, Bernard Heidsieck, poésie action, 1996, p. 136.

${ }^{11}$ Bobillot, op. cit., p. 40

12 Idem, p. 116.

${ }^{13}$ Henri Michaux, Par des traits, 1984 e Par la voie des rythmes, 1974.

14 Tratamos deste tema mais detalhadamente no artigo "Composer par la voie de rythmes: Beckett, Michaux, Deleuze", apresentado no XX Congresso da AILC (Associação Internacional de Literatura Comparada), a constar na publicação oficial do evento (no prelo). 
${ }^{15}$ Gilles Deleuze, Francis Bacon, logique de la sensation, 1982, p. 31.

16 Berio, op. cit., p. 190.

17 Referimo-nos aqui sobretudo ao verbete "Voz", que é assinado por outros dois integrantes do grupo de Sarrazac, no entanto, sabe-se que o livro é resultante das discussões de todo o grupo em torno das ideias de Sarrazac. JeanPierre Sarrazac, Léxico do drama moderno e contemporâneo, p. 185-189.

18 Sarrazac, op. cit., p. 187.

${ }^{19}$ Hans-Thies Lehmann, O teatro pós-dramático, p. 261.

${ }^{20}$ Sarrazac, op. cit., p. 186.

21 Tal aspecto de uma composição passos-a-passo onde as soluções de continuidade são locais está abordado mais detalhadamente em Silvio Ferraz, "La formule de la Ritournelle", que tem por base o conceito de ritornelo trabalhado por Gilles Deleuze e Félix Guattari em Mil Platôs.

22 Félix Guattari, "L'hétérogenèse dans la création musicale”, Chimères, p. 1.

23 Utilizamos aqui a diagramação original do poema, centralizado na página. Ghérasim Luca, Héros-limite, suivi de La Chant de la carpe et de Paralipomenes. 2001, p. 169 e p. 176

${ }^{24}$ Samuel Beckett, Poèmes, suivi de Mirlitonnades, 1978, p. 26-27.

25 Samuel Beckett, O inominável, trad. bras., 2009, p. 185.

${ }^{26}$ Christophe Tarkos, Anachronisme, 2001, p. 60.

${ }^{27}$ Idem, p. 61.

${ }^{28}$ Idem, p. 67.

${ }^{29}$ Christophe Tarkos, Le Signe =, 1999, p. 29.

${ }^{30}$ Embora ao longo do século XX tenha-se cunhado um pensamento de que a obra de Arnold Schoenberg, tenha aberto caminhos para o futuro, tal qual afirmou Adorno em seu Filosofia da Nova Musica, de 1948, hoje não é difícil reconhecer que ao mesmo tempo em que tais portas pareciam abertas, mantinham-se fechadas outras através da manutencão dos mecanismos composicionais classsico-românticos, tanto quanto a aspectos formais quanto ao tratamento do material composicional rítmico e melódico (Cf. Arnold Schoenberg, Fundamentos da Composicão Musical, 1991; Theodor W. Adorno, Musique et nouvelle musique" e "Vers une musique informelle", In Quase una fantasia, 1963.)

31 "Figuras diversas se sucedem umas às outras conservando um detalhe comum, às vezes uma figura se repete idêntica, ainda que à distância, mas com diferentes detalhes. As vezes são figuras que retornam imutáveis. As vezes, enfim, eventos sem relação. Tudo isto é distribuído ẹm um arco de tempo muito diversificado e advém em um contextọ sempre mutante onde as figuras adquirem diversos graus de implicacão, de reconhecimento e de sobrevivência. Creio que o sentido do discurso resida propriamente na sua ausência. Âs "palavras" e as "frases" de Notturno deslizam umas nas outras, desaparecem e reaparecem, se entreolham, morrem". Berio, Luciano, "Notturno (1995)", Scritti sulla musica, 2013, p. 299.

32 "on a un petit bidon./ un bidon d'huile/ sur la table./ un petit bidon vide./un petit bidon normal/ normalement. sur la table// avec du vide dedans./ il est fermé mais il est vide./ si on regarde dedans le petit bidon il y a du vide. on n'a rien./ on regarde sur la table et on voit un petit bidon qui ne déborde pas de la table./ le petit bidon reste bien a sa place./ il ne bouge pas./ il ne déborde pas comme une grande masse blanche qui viendrait par dessus la table et qui viendrai deborder la table et qui viendrai se mettre dessous la table. il reste au dessus de la table./ il est totalement vide./ il ne se passe rien (...)" Transcrição livre de improvisaçåo de Cristophe Tarkos, sinalizando as pausas realizadas pelo poeta em sua performance. Christophe Tarkos, Expressif, le petit bidon improvisations et lectures, 2001 . 